\title{
Effect of Penetration of Wind DGs on Transient Stability of Captive Power Generation Units
}

\author{
P. S. D. Bhimaraju, K. V. S. Ramachandra Murthy, K. Ravindra
}

\begin{abstract}
This paper presents the analysis of transient stability for industrial generators and the effect of distributed generator units on transient stability has been studied. Here we considered IEEE 39 busses system having one utility bus and 9 captive generation units.

It is observed that the voltages at all the buses, decreased when Wind Power DGs are connected. Voltages at all the buses in the system are reduced because of reactive power demand by Induction Generators. The total load of the system is 121.57 MW + j 56.6 MVAr. Critical Clearing Times (CCTs) are obtained without introducing any DG and later, CCTs are obtained with four Wind Power DGs. Their capacities are 7.0 MW, 8.0 MW, 9.0 $\mathrm{MW}$ and $5.0 \mathrm{MW}$ with $0.8,0.85,0.9$ and 0.95 power factors respectively. The Induction Generators used in Wind DGs inject active power and consume reactive power.

It is observed that the voltages at all the buses, decreased when Wind Power DGs are connected. Voltages at all the buses in the system are reduced because of reactive power demand by Induction Generators. LLLG faults at seven load buses and nine Generator buses and are considered for obtaining Critical Clearing Times (CCT). It is observed that transient stability of system is improved by placing DGs. DGs used in this system improves the critical clearing time (CCT) for faults at load buses by $30 \%$ and faults at generator buses by $15.5 \%$. The detailed results are tabulated in this paper.
\end{abstract}

Keywords : Critical Clearing Time, Distributed, generators, Transient Stability.

\section{INTRODUCTION}

The maximum allowable value of the clearing time for the system to remain stable is known as critical clearing time (CCT). Wind Generator is a dynamic machine. By connecting dynamic machinery to the grid, overall intertia of the grid increases. Some times it is useful to increase the overall stability. But, when solar power plants are integrated with the grid, it does not add to inertia of the system as it is static system. There will be problems associated with frequency when solar is integrated with grid, where as when wind power units are integrated with the grid, the integration is done through the combination of converter and inverter units. The only requirement with

Revised Manuscript Received on February 25, 2020.

* Correspondence Author

P.S.D Bhimaraju, Department of EEE, Aditya Engineering College / Kakinada, India

K. V. S. R. Murthy, Department of EEE, Aditya Engineering College / Kakinada, India.

K. Ravindra, Department of EEE, UCEK /JNTUK / Kakinada, India.

(C) The Authors. Published by Blue Eyes Intelligence Engineering and Sciences Publication (BEIESP). This is an open access article under the CC BY-NC-ND license (http://creativecommons.org/licenses/by-nc-nd/4.0/) induction generators is, it absorbs reactive power from the grid. On the same 39 Bus system, the authors have done similar analysis by placing the Solar DGs and published their results. The current work replaces the Solar DGs [1] with Wind DGs and observe the transient stability analysis.

Olulope et al analyzed stability of the systems with hybrid DGs on stability [2]. Azmy examined the effect of fuel cell on stability of system [3]. Several researchers worked on single DG source connected the power system [4-6].

The system inertia for PV is low [7]. Outputs of both PV and Wind Generation units are weather dependent. A grid connected hybrid scheme for residential power supply was presented in [8].

In this work, without DGs, CCTs were obtained considering faults at seventeen locations. Keeping the load constant, 4 Wind DGs are placed simultaneously by reducing the active power generation on other generator units and grid. Section 2 presents system modelling, Section 3 presents results and section 4 presents conclusions.

\section{SYSTEM MODELLING}

In this section, General Structure of the Power System, Generator Modelling and Load modelling are presented.

\section{A. General Structure of Power System}

The power system description is taken from [1]. Fig 1 represents power system model.

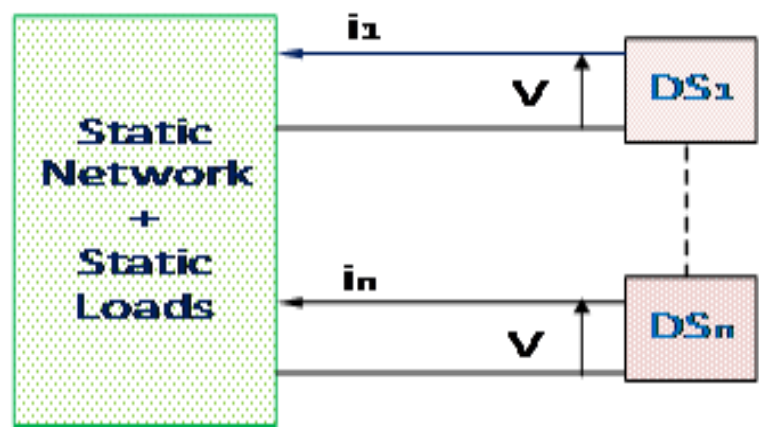

Fig.1 Power System Representation

\section{B. Generator Equations:}

Stator is represented by the two axes ( $d$ and q axes) equivalent of the three-phase winding. The equations of flux linkages associated with $\mathrm{d}$ and $\mathrm{q}$ axes, current equations of $\mathrm{d}$ and $\mathrm{q}$ axis, machine terminal voltages of direct and quadrature axis, voltagesof Kron's reference frame are presented as in [1] which was modeled by the same group of researchers.

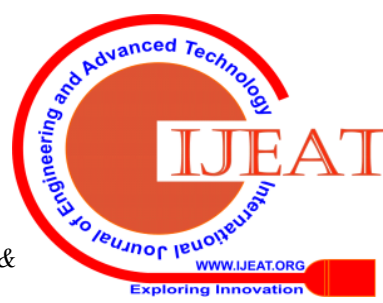




\section{Effect of Penetration of Wind DGs on Transient Stability of Captive Power Generation Units}

Similarly related damper winding equation which is nothing but, rate of change of direct and quadrature axis voltages are presented as in [1].

The electrical torque equation, the swing equation are taken from derivations from KR Padiyar [9].

The Fig. 2 shows generator representation on network side. Thus the final equation can be written as,

$$
E_{Q}^{\prime}+j\left(E_{D}^{\prime}+E_{\text {dummy }}\right)+j\left(i_{Q}+j i_{D}\right) x_{d}^{\prime}=\left(v_{Q}+j v_{D}\right)
$$

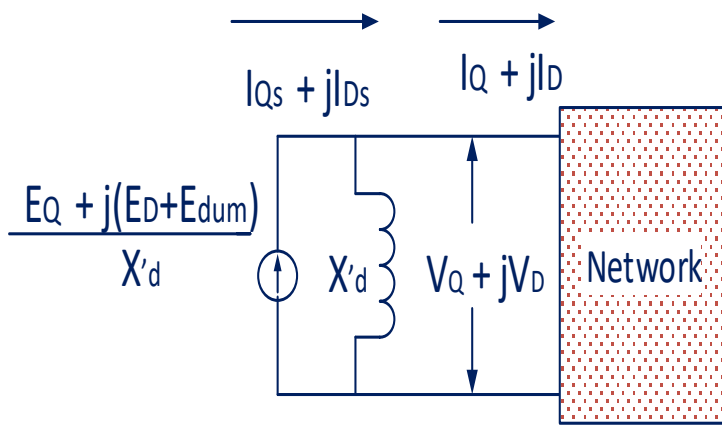

\section{Fig. 2 Generator Representation on Network Side}

Industrial system with 39 Buses is considered with one utility bus and nine smaller units out of which one is a slack bus. Industry imports a fraction of total power required and remaining is met by smaller generators which are owned by industry. The system consists of 39 Buses, 34 lines and 12 transformers. Bus No.6 is considered as slack bus.

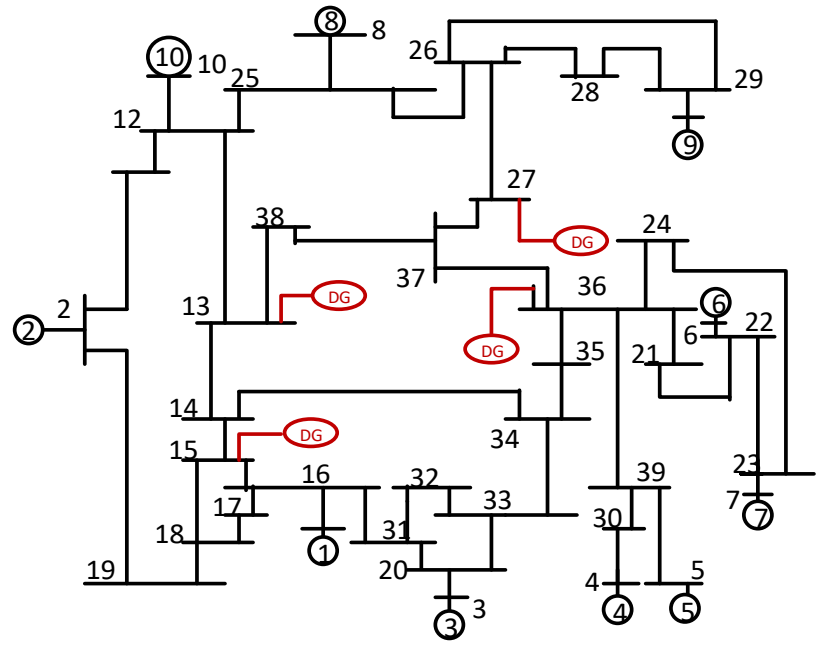

Fig. 3 IEEE 39 Bus Test System

The 2-11 and 2-19 are the tie lines. DGs of total capacity 29MW are connected at four different buses. The DG penetration considered in this work is, $24 \%$. Fig. 3 shows the 39 Bus system.Critical clearing time is calculated for fault at various buses.

Two case studies have been conducted. At the first level, with out including any DG, transient stability study is conducted. At the second level, Wind Power DGs are placed at four load buses and CCTs are obtained for various faults.

\section{RESULTS}

In this work, transient stability analysis of industrial generator units is carried out using simulation using Simulink.

\section{A. Variation of CCTs with Wind DGs :}

$7 \mathrm{MW}$ DG is connected at bus number 13, $8 \mathrm{MW}$ DG is connected at bus number 15, 9 MW DG is connected at bus number 27 and 5 MW DG is connected at bus number 36 . Total injected power through DGs amounts to $24 \%$ of load demand on the system.

Voltages with DG and without DG is shown in table I. It is observed that voltage magnitude decreased at all the buses due to the nature of absorbing reactive power by Induction Generators. But voltage angles where ever negative have changed to positive and some angles changed from small positive to large positive. Voltage at Bus 13 changed from 0.9741 to $0.9397 \mathrm{pu}$. Voltage at Bus 15 changed from 0.957 to 0.9296 pu. Voltage at Bus 27 changed from 0.9586 to $0.9161 \mathrm{pu}$. Voltage at Bus 36 changed from 0.9651 to $0.94 \mathrm{pu}$.

The effect of DG placement at at Bus 15 can be analysed as a sample case study. Before placement of DG at Bus 15, there is a an active power flow from Bus 16 to Bus 15. The amount of power flow is 1.6 MW. The power flow after placement of DG is, $1.9 \mathrm{MW}$ from Bus 15 to 16 . This has resulted in reduction power flow from Gen 1 to Bus 16 The power flow reduced from 5.95 MW to $4.95 \mathrm{MW}$. As the real power flow output of Gen 1 reduced, critical clearing time for the fault at Bus No. 1 increased from 0.37 second to 0.43 second.

Before connecting DGs, power flow from Bus 2 to Bus 11 is $20.47 \mathrm{MW}$ and from Bus2-19 is 23.48 MW. After connecting the DGs at Bus 13 and Bus 15, the power flows are 15.24 MW and 18.72 respectively. This results in improvement of critical clearing time from 0.5 second to 0.55 seconds. It is the Gen 10 that goes unstable in both the cases as Bus 2 is modeled with large inertia constant.

CCT for the fault at Generator Bus 3 is improved from 0.31 seconds to 0.37 seconds. Decrease in power generation at Bus 3 from 4.20 MW to $3.20 \mathrm{MW}$ is the reason for improvement in CCT after placement of DGs.

The DG placement at Bus No. 36 also affects the CCT at Gen Bus 4 and Bus 5. Power flow reduced from Bus No.4 to Bus No.30 from 4.58 MW to 3.58 MW which reduced the burden on Gen 4. CCT changed from 0.27 Seconds to 0.34 Seconds after placement of DG.

The power flow from Bus 5 to Bus 39 is reduced after placing DG at Bus No. 36. Before placement of DG, it is 4.82 MW and after placement of DG, it is 3..82 MW. Which results in improvement of CCT of Gen Bus 5 from 0.33 seconds to 0.39 seconds

The CCT of fault at Generator Bus 7 changed from 0.27 seconds to 0.32 seconds after placing DGs. The nearest DG placed is at Bus 36. There is a connection between Bus 36 to Bus 24 and from Bus 24 to Bus 23. Power flow increased from 3.39 to 5.59 from Bus 36 to Bus 24. Power flow increased from $-1.70 \mathrm{MW}$ to $0.50 \mathrm{MW}$ from Bus 24 to Bus 23. All this resulted in reduction of power produced by Gen 7. Gen 7 produces $6.6 \mathrm{MW}$ before placement of DG and it produces 5.6 MW after placement of DGs.

Reduction in active power generation reduces the phase angle hence, it can withstand fault condition for more duration. 
Power generated from Bus 8 is reduced from 5.9 MW to 4.9 MW after placement of DG. This resulted in improvement of CCT for the fault at Gen No.8. The CCT is changed from 0.27 seconds to 0.31 seconds.

The effect of DG at Bus 27 can be studied in the following way. Before DG placement at Bus 27, there is an active power flow of $3.48 \mathrm{MW}$ from Bus No. 26 to Bus 27. After placement of DG, the power flow is 0.247 from Bus No. 26 to Bus 27. This has resulted in reduction of power flow from Bus29 to Bus 28. Before placement of DG, from Bus 29 to Bus 28, there is an active power flow of 2.83 MW and after placement, it is $2.33 \mathrm{MW}$. For a fault that takes place at Gen 9, CCT is 0.37 second before DG placement where as after placement, it is 0.39 second. It can be understood that larger is the change in burden on the Generator bus, between the two cases, greater will be the change in CCT of the Generator Bus.

The effect of placing DG at Bus 13 can be studied in this section. Before placement of DG at Bus 13, there is a power flow of $13.68 \mathrm{MW}$ from Bus 12 to Bus 13. After placement of DG, there is a power flow of 8.92 MW from Bus 12 to Bus 13. This has direct impact on power flow from Gen 10 to Bus No. 12. Before placement of DG, Gen 10 supplied 4.8 MW. With DG, the burden has reduced to 3.8 MW. CCT for fault at Gen Bus 10, before placement is 0.37 second where as, after placement it is 0.42 Second.

A wind generator is placed at Bus 13. This has adverse affect on CCT at Bus 11 . Induction generator requires reactive power. From Bus 11 to Bus 12, the active power flow reduced from 19.43 MW to 14.21. But, reactive power increased from 1.5 MVAR to 5.86 MVAR. The raise in reactive power has adverse affect on CCT for the fault at Bus 11. CCT has increased from 0.36 seconds to 0.39 seconds.

CCT for the fault at Bus No.12 is changed from 0.30 seconds to 0.32 seconds. There is a drastic reduction in active power flow from Bus 12 to Bus 13 after connecting DGs. Before placement of DGs, the power flow Bus 12 to Bus 13 is, $13.68 \mathrm{MW}$. After DG placement, it is $8.92 \mathrm{MW}$. Reactive power flow from Bus 12 to Bus 13 is 4.61 MVAR before placement of DGs and after placement it is, 8.67. The raise in reactive power flow is dominated by reduction in active power flow from Bus 12 to Bus 13 and hence, the CCT has improved slightly.

CCT for the fault at Bus No.21 is changed from 0.29 seconds to 0.45 seconds. There is a drastic change in active power flow from Bus 21 to Bus 36 after connecting DGs. Before placement of DGs, the power flow Bus 21 to Bus 36 is, 2.77 MW. After DG placement, it is 7.14 MW from Bus 36 to Bus 21. Reactive power flow from Bus 21 to Bus 36 is 1.02 MVAr before placement of DGs and after placement it is, 3.33 MVAr. The raise in reactive power flow is dominated by change in direction and magnitude of active power flow from Bus 21 to Bus 36.

The effect of DG placement at at Bus 15 on CCT at Bus 16 can be analysed. Before placement of DG at Bus 15 , there is a an active power flow from Bus 16 to Bus 15 . The amount of power flow is 1.6MW. The power flow after placement of DG is, $1.9 \mathrm{MW}$ from Bus 15 to 16 . This results in large improvement in the CCT for the fault at Bus 16. Before DG placement, the CCT is 0.41seconds where as after DG placement, it is 0.48 Second. The power flow increased from Bus 16 to Bus 31 from 4.53 MW to 5.72 MW.

Placement of DG at Bus 15 has effect on CCT at Bus 19. Before placement of DG, power flow from Bus 18 to Bus 15 is $6.86 \mathrm{MW}$ and after placement of DG, it is 3.46 MW. CCT for the fault at Bus 19 before placement of DG is 0.42 seconds and after placement of DGs is, 0.51 seconds.

The effect of placing DG at Bus 36 on the fault at Bus No. 35 can be easily understood. Before placing DG at Bus No.36, the CCT for the fault at Bus 35 is 0.34 second and after placing DG the CCT is 0.54 second.

CCT for the fault at Bus 36 is changed from 0.29 seconds to 0.42 seconds. The placement of DG at 36 itself is the reason for improvement in CCT.

Critical clearing times for various generator and load buses for the faults are shown in Table II and Table III. It is observed that for the faults at generator buses, CCTs are increased by $15.5 \%$. CCTs are increased by $30 \%$ on average. For placing the Wind DGs of 29 MW, a total active power of $18 \mathrm{MW}$ of captive power generation is reduced. Remaining is balanced at slack bus.

Table IV shows the real and reactive power flows in the lines. The percentage change in power flows at the nearby buses is proportional to the change in CCTs is the fact established by this research

\section{CONCLUSION}

In this work, effect of wind Power DGs on transient stability of the industrial power system is analysed. Four Wind DGs of 7.0 MW, 8.0 MW, 9.0 MW and 5.0 MW with $0.8,0.85,0.9$ and $0.95 \mathrm{pf}$ respectively are considered. It is observed that for the faults at generator buses, Critical Clearing Times are increased by $15.5 \%$. CCTs for faults at load buses are increased by $30 \%$ on average. The change in critical clearing time is low for faults at Generator buses and the same is high at load buses. There is a direct relation between change in CCT and the deviation in power flow on transmission lines in between the faulted bus and generators which become unstable. 
Effect of Penetration of Wind DGs on Transient Stability of Captive Power Generation Units

Table I : Voltages magnitudes and Voltage angles before and after placing Wind DGs

\begin{tabular}{|c|c|c|c|c|c|c|c|c|c|}
\hline \multirow[b]{2}{*}{$\begin{array}{l}\text { Bus } \\
\text { No. }\end{array}$} & \multicolumn{2}{|c|}{ Before DG placement } & \multicolumn{2}{|c|}{ After DG placement } & \multirow[b]{2}{*}{$\begin{array}{l}\text { Bus } \\
\text { No. }\end{array}$} & \multicolumn{2}{|c|}{ Before DG placement } & \multicolumn{2}{|c|}{ After DG placement } \\
\hline & Voltage & Angle(Deg) & Voltage & $\begin{array}{l}\text { Angle } \\
\text { (Deg) }\end{array}$ & & Voltage & $\begin{array}{l}\text { Angle } \\
\text { (Deg) }\end{array}$ & Voltage & $\begin{array}{l}\text { Angle } \\
\text { (Deg) }\end{array}$ \\
\hline 1 & 1.016 & -0.9251 & 1.016 & 14.5609 & 21 & 0.966 & -11.9323 & 0.941 & 1.4551 \\
\hline 2 & 1.035 & 0.6944 & 1.035 & 14.9199 & 22 & 1.0068 & -8.3431 & 0.9919 & -0.08 \\
\hline 3 & 0.98 & -3.3686 & 0.98 & 10.6394 & 23 & 1.0055 & -8.8107 & 0.9925 & 0.1064 \\
\hline 4 & 1.038 & -9.0227 & 1.038 & 2.5923 & 24 & 0.9635 & -12.1902 & 0.9385 & 1.3864 \\
\hline 5 & 1.01 & -8.1657 & 1.01 & 4.565 & 25 & 0.9877 & -4.1411 & 0.9928 & 11.1829 \\
\hline 6 & 1.1 & 0 & 1.1 & 0 & 26 & 0.9896 & -10.2094 & 0.9883 & 6.8117 \\
\hline 7 & 1.056 & -3.575 & 1.056 & 3.9069 & 27 & 0.9586 & -13.1495 & 0.9161 & 7.0093 \\
\hline 8 & 1.067 & 3.1947 & 1.067 & 17.2279 & 28 & 0.9897 & -10.2621 & 0.9887 & 6.729 \\
\hline 9 & 0.996 & -10.0674 & 0.996 & 6.85 & 29 & 0.9911 & -10.3067 & 0.99 & 6.6573 \\
\hline 10 & 1.079 & 4.661 & 1.079 & 18.1781 & 30 & 0.9873 & -13.5375 & 0.9731 & -0.9383 \\
\hline 11 & 1.0331 & 0.6022 & 1.0332 & 14.8737 & 31 & 0.9322 & -8.3862 & 0.9128 & 7.1482 \\
\hline 12 & 1.0267 & 0.2133 & 1.0266 & 14.6676 & 32 & 0.8767 & -11.7454 & 0.8556 & 3.4459 \\
\hline 13 & 0.9741 & -6.5846 & 0.9397 & 10.5208 & 33 & 0.9328 & -9.3528 & 0.913 & 5.7834 \\
\hline 14 & 0.9393 & -9.8424 & 0.9109 & 6.2084 & 34 & 0.9468 & -10.4025 & 0.9228 & 4.5893 \\
\hline 15 & 0.957 & -6.3764 & 0.9296 & 10.544 & 35 & 0.9614 & -11.9312 & 0.937 & 1.9095 \\
\hline 16 & 0.9577 & -6.1179 & 0.9367 & 10.1822 & 36 & 0.9651 & -12.0105 & 0.94 & 1.7072 \\
\hline 17 & 0.9694 & -4.9055 & 0.9566 & 10.6236 & 37 & 0.9661 & -11.9019 & 0.9437 & 2.3793 \\
\hline 18 & 0.9892 & -3.1348 & 0.9804 & 12.0391 & 38 & 0.9668 & -10.3509 & 0.9385 & 4.9589 \\
\hline 19 & 1.0315 & 0.6356 & 1.0317 & 14.9024 & 39 & 0.969 & -12.0592 & 0.944 & 1.4974 \\
\hline 20 & 0.9338 & -8.635 & 0.916 & 6.5511 & & & & & \\
\hline
\end{tabular}

Table II. CCT for Faults on Generator Buses with Wind DGs.

\begin{tabular}{|c|c|c|c|c|}
\hline \multirow{2}{*}{ Bus no. } & Before DG placement & $\begin{array}{c}\text { After DG placement } \\
\text { (wind) }\end{array}$ & Percentage Change & $\begin{array}{c}\text { Generator that becomes } \\
\text { unstable }\end{array}$ \\
\cline { 2 - 4 } & CCT (in ms) & CCT (in ms) & 16 & Generator 1 \\
\hline 1 & 370 & 430 & 10 & Generator 10 \\
\hline 2 & 500 & 550 & 19 & Generator 3 \\
\hline 3 & 310 & 370 & 26 & Generator 4 \\
\hline 4 & 270 & 340 & 18 & Generator 5 \\
\hline 7 & 330 & 390 & 18 & Generator 7 \\
\hline 9 & 270 & 320 & 15 & Generator 8 \\
\hline 10 & 270 & 310 & 5 & Generator 9 \\
\hline
\end{tabular}


Table III. CCT for Faults on load buses with Wind DGs.

\begin{tabular}{|c|c|c|c|c|}
\hline & Before DG placement & $\begin{array}{c}\text { After DG placement } \\
\text { (wind) }\end{array}$ & Percentage Change & $\begin{array}{c}\text { Generator that becomes } \\
\text { unstable }\end{array}$ \\
\hline Bus no. & CCT (in ms) & CCT (in ms) & & Generator 10 \\
\hline 11 & 360 & 390 & 7 & Generator 10 \\
\hline 12 & 300 & 320 & 17 & Generator 1 \\
\hline 16 & 410 & 480 & 21 & Generator 1 \\
\hline 19 & 420 & 510 & 55 & Generator 4 \\
\hline 21 & 290 & 450 & 59 & Generator 4 \\
\hline 35 & 340 & 540 & 45 & Generator 4 \\
\hline 36 & 290 & 420 & & \\
\hline
\end{tabular}

\section{REFERENCES}

1. K. V. S R. Murthy, P. S. D. B. Raju, K. Ravindra, "Effect of penetration of solar DGs on transient stability of captive power generation units", International journal of Engineering and Advanced Technology(IJEAT), Aug. 2019.

2. Olulope, Folly, G. K. V. Moorthy, "Modeling and simulation of hybrid distributed generation and its impact on transient stability of power system", Proc. IEEE ICIT, Feb. 2013.

3. A.M.Azmy, Simulation and Management of Distributed Generation units using intelligent techniques, Doctoral Report, University of Duisburg, Essen 2005

4. T. T. Quoc, Thanh, "Stability analysis for the distribution networks with distributed generation", Proc. IEEE/PES T \& D Conference, Vol. 1-3, Dallas, May 21-26, 2006

5. Thong, Driesen, Belmans, "Transmission system operation concerns with high penetration level of distributed generation", Universities power and Engineering Conference UPEC, pp.867-8717, 4-6 Sept., 2007.

6. Momoh, Boswell, "Improving power Grid Efficiency using Distributed Generation”, Proced. of International Conference on power system operation and planning, pp.11-17, Jan., 2007

7. Arutchelvi Meenakshisundaram, Daniel Samuel Arul. "GRID connected hybrid dispersed power generators based on PV array and wind-driven induction generator", Journal of Electrical Engineering 2009;60(6): pp. 313-20.

8. Joanne Hui, Alireza Bakhshai, 'A hybrid wind-solar energy system: a new rectifier stage topology'. In: Applied Power Electronics Conference, $201025^{\text {th }}$ Annual IEEE, 21 to 25 Feb.,2010, pp. 155-61.

9. K R Padiyar, "Power System Dynamics: Stability and Control", B S Publications, $2^{\text {nd }}$ Edition, 2018.

Table IV. Real and Reactive power flows in the lines

\begin{tabular}{|c|c|c|c|}
\hline From bus & To bus & Real power & Reactive power \\
\hline 27 & 37 & 4.4043 & -1.98174 \\
\hline 38 & 37 & 4.78466 & -0.95783 \\
\hline 36 & 24 & 5.59159 & 0.90355 \\
\hline 36 & 21 & 7.14022 & -3.3316 \\
\hline 39 & 36 & 1.07135 & 6.17236 \\
\hline 37 & 36 & 9.13474 & -3.18114 \\
\hline 35 & 36 & 0.93084 & -3.86155 \\
\hline 34 & 35 & 4.17862 & -2.41735 \\
\hline 33 & 34 & 1.64807 & -1.08437 \\
\hline 29 & 28 & 2.33217 & 3.5211 \\
\hline 26 & 29 & 0.22042 & -4.11051 \\
\hline 26 & 28 & 1.82696 & -2.64624 \\
\hline
\end{tabular}


Effect of Penetration of Wind DGs on Transient Stability of Captive Power Generation Units

\begin{tabular}{|c|c|c|c|}
\hline 26 & 27 & 0.24787 & 4.71621 \\
\hline 25 & 26 & 6.08006 & -0.25219 \\
\hline 24 & 23 & 0.50198 & -1.63113 \\
\hline 23 & 22 & 0.33612 & -0.05268 \\
\hline 21 & 22 & 2.39322 & -5.94077 \\
\hline 20 & 33 & 2.64416 & 0.38293 \\
\hline 31 & 20 & 1.94633 & -0.89134 \\
\hline 2 & 19 & 18.72113 & 14.83129 \\
\hline 19 & 18 & 16.66612 & 14.42729 \\
\hline 18 & 17 & 5.44159 & 4.62162 \\
\hline 16 & 31 & 5.72255 & 2.32984 \\
\hline 17 & 16 & 0.88225 & 1.96921 \\
\hline 18 & 15 & 3.46373 & 5.7083 \\
\hline 15 & 16 & 1.90873 & -2.6963 \\
\hline 14 & 34 & 2.54273 & -1.45859 \\
\hline 15 & 14 & 7.41722 & 1.51204 \\
\hline 13 & 38 & 6.41596 & -0.22616 \\
\hline 13 & 14 & 3.09492 & 1.09688 \\
\hline 12 & 25 & 6.41909 & -1.04099 \\
\hline 12 & 13 & 8.92484 & 8.67323 \\
\hline 11 & 12 & 14.21782 & 5.86956 \\
\hline 2 & 11 & 15.24008 & 4.83513 \\
\hline 39 & 30 & 2.72407 & -2.06981 \\
\hline 5 & 39 & 3.82 & 4.60036 \\
\hline 33 & 32 & 0.99266 & 1.49156 \\
\hline 31 & 32 & 1.36553 & 1.34052 \\
\hline 4 & 30 & 3.58 & 3.72726 \\
\hline 9 & 29 & 6.99993 & 8.83805 \\
\hline 8 & 25 & 4.9 & 3.5403 \\
\hline 7 & 23 & 2.6 & 2.50195 \\
\hline 6 & 22 & 0.10658 & 8.31242 \\
\hline 3 & 20 & 3.2 & 3.24995 \\
\hline 1 & 16 & 4.95309 & 5.45878 \\
\hline 10 & 12 & 3.8 & 3.17297 \\
\hline
\end{tabular}

